Cochrane Database of Systematic Reviews

\title{
Radiotherapy versus open surgery versus endolaryngeal surgery (with or without laser) for early laryngeal squamous cell cancer
} (Review)

Warner L, Chudasama J, Kelly CG, Loughran S, McKenzie K, Wight R, Dey P

Warner L, Chudasama J, Kelly CG, Loughran S, McKenzie K, Wight R, Dey P.

Radiotherapy versus open surgery versus endolaryngeal surgery (with or without laser) for early laryngeal squamous cell cancer.

Cochrane Database of Systematic Reviews 2014, Issue 12. Art. No.: CD002027.

DOI: 10.1002/14651858.CD002027.pub2. 
TABLE OF CONTENTS

HEADER 1

ABSTRACT

PLAIN LANGUAGE SUMMARY

BACKGROUND

OBJECTIVES

METHODS

RESULTS

Figure 1.

DISCUSSION

AUTHORS' CONCLUSIONS

ACKNOWLEDGEMENTS

REFERENCES

CHARACTERISTICS OF STUDIES

APPENDICES

WHAT'S NEW

HISTORY

CONTRIBUTIONS OF AUTHORS

DECLARATIONS OF INTEREST

SOURCES OF SUPPORT 
[Intervention Review]

\title{
Radiotherapy versus open surgery versus endolaryngeal surgery (with or without laser) for early laryngeal squamous cell cancer
}

\author{
Laura Warner $^{1}$, Jessal Chudasama 2 , Charles G Kelly ${ }^{3}$, Sean Loughran ${ }^{4}$, Kenneth McKenzie ${ }^{5}$, Richard Wight ${ }^{6}$, Paola Dey ${ }^{7}$ \\ 1Department of Otolaryngology, Head and Neck Surgery, North Manchester General Hospital, Pennine Acute Hospitals NHS Trust, \\ Manchester, UK. ${ }^{2}$ Lancashire Teaching Hospitals NHS Foundation Trust, Royal Preston Hospital, Preston, UK. ${ }^{3}$ Northern Centre for Cancer \\ Treatment, Newcastle General Hospital, Newcastle upon Tyne, UK. ${ }^{4}$ Department of Otolaryngology, Head and Neck Surgery, Manchester \\ Royal Infirmary, Central Manchester University Hospitals Foundation Trust, Manchester, UK. ${ }^{5}$ Department of ENT Surgery, Glasgow Royal \\ Infirmary, Glasgow, UK. ${ }^{6}$ Department of ENT Surgery, North Riding Infirmary, Middlesborough, UK. ${ }^{7}$ School of Postgraduate Medical and \\ Dental Education, University of Central Lancashire, Preston, UK
}

Contact address: Laura Warner, Department of Otolaryngology, Head and Neck Surgery, North Manchester General Hospital, Pennine Acute Hospitals NHS Trust, Delaunays Road, Manchester, M8 5RB, UK. lauratod@doctors.org.uk.

Editorial group: Cochrane ENT Group

Publication status and date: New search for studies and content updated (no change to conclusions), published in Issue 12, 2014.

Citation: Warner L, Chudasama J, Kelly CG, Loughran S, McKenzie K, Wight R, Dey P. Radiotherapy versus open surgery versus endolaryngeal surgery (with or without laser) for early laryngeal squamous cell cancer. Cochrane Database of Systematic Reviews 2014, Issue 12. Art. No.: CD002027. DOI: 10.1002/14651858.CD002027.pub2.

Copyright ( 2014 The Cochrane Collaboration. Published by John Wiley \& Sons, Ltd.

\section{A B S T R A C T}

\section{Background}

This is an update of a Cochrane review first published in The Cochrane Library in Issue 2, 2002 and previously updated in 2004,2007 and 2010.

Radiotherapy, open surgery and endolaryngeal excision (with or without laser) are all accepted modalities of treatment for early-stage glottic cancer. Case series suggest that they confer a similar survival advantage, however radiotherapy and endolaryngeal surgery offer the advantage of voice preservation. There has been an observed trend away from open surgery in recent years, however equipoise remains between radiotherapy and endolaryngeal surgery as both treatment modalities offer laryngeal preservation with similar survival rates. Opinions on optimal therapy vary across disciplines and between countries.

\section{Objectives}

To compare the effectiveness of open surgery, endolaryngeal excision (with or without laser) and radiotherapy in the management of early glottic laryngeal cancer.

\section{Search methods}

We searched the Cochrane Ear, Nose and Throat Disorders Group Trials Register; the Cochrane Central Register of Controlled Trials (CENTRAL 2014, Issue 8); PubMed; EMBASE; CINAHL; Web of Science; Cambridge Scientific Abstracts; ICTRP and additional sources for published and unpublished trials. The date of the most recent search was 18 September 2014.

\section{Selection criteria}

Randomised controlled trials comparing open surgery, endolaryngeal resection (with or without laser) and radiotherapy.

\section{Data collection and analysis}

We used the standard methodological procedures expected by The Cochrane Collaboration. 


\section{Main results}

We identified only one randomised controlled trial, which compared open surgery and radiotherapy in 234 patients with early glottic laryngeal cancer. The overall risk of bias in this study was high.

For T1 tumours, the five-year survival was $91.7 \%$ following radiotherapy and $100 \%$ following surgery and for T2 tumours, $88.8 \%$ following radiotherapy and $97.4 \%$ following surgery. There were no significant differences in survival between the two groups.

For T1 tumours, the five-year disease-free survival rate was $71.1 \%$ following radiotherapy and $100.0 \%$ following surgery, and for the $\mathrm{T} 2$ tumours, $60.1 \%$ following radiotherapy and $78.7 \%$ following surgery. Only the latter comparison was statistically significant $(\mathrm{P}$ value $=$ 0.036), but statistical significance would not have been achieved with a two-sided test.

Data were not available on side effects, quality of life, voice outcomes or cost.

We identified no randomised controlled trials that included endolaryngeal surgery. A number of trials comparing endolaryngeal resection and radiotherapy have terminated early because of difficulty recruiting participants. One randomised controlled trial is still ongoing.

\section{Authors' conclusions}

There is only one randomised controlled trial comparing open surgery and radiotherapy but its interpretation is limited because of concerns about the adequacy of treatment regimens and deficiencies in the reporting of the study design and analysis.

\section{PLAIN LANGUAGE SUMMARY}

\section{Radiotherapy versus open surgery versus endolaryngeal surgery (with or without laser) for early larynx cancer}

\section{Background}

Cancer of the larynx or voice box usually begins in the glottis (vocal cords) as a squamous cell cancer (cancer in the membranes). Most people survive these cancers when they get treatment early, before the cancer spreads further into the larynx and surrounding area. Options include radiotherapy, open surgery where access is through the neck or, more commonly now, endolaryngeal excision whereby the throat is reached through the mouth, sometimes with a laser.

\section{Study characteristics}

This review of trials identified just one trial including 234 patients with early glottic cancer, which compared radiotherapy to open surgery. This was a multicentre randomised controlled trial undertaken in the former Soviet Union, Hungary and Czechoslovakia. Patients were followed up for five years and recurrence-free and survival rates were measured.

\section{Key results}

The results of this trial showed that there was no significant difference in survival between patients treated with radiotherapy or open surgery.

Further data from trials comparing radiotherapy and endolaryngeal surgery are needed to determine the best way of treating early laryngeal cancer, however a number of studies have been abandoned because of difficulties in recruiting participants. One trial is still ongoing.

We found that there is not enough evidence to show which form of treatment might be better for people with early-stage larynx cancer.

\section{Quality of the evidence}

The included study is of low quality. The evidence in this review is up to date to September 2014. 


\section{B A C K G R O U N D}

This is an update of a Cochrane review first published in The Cochrane Library in Issue 2, 2002 and previously updated in 2004, 2007 and 2010.

\section{Description of the condition}

Over 150,000 new cases of laryngeal cancer are diagnosed each year (GLOBOCAN 2012); the highest rates are observed in Southern and Eastern Europe (Parkin 1997). Men are more likely to develop laryngeal cancer than women. Smoking and alcohol are proven risk factors and the temporal decline in incidence of this cancer in some populations is consistent with a decline in the consumption of tobacco (Coleman 1993).

Laryngeal cancers most commonly arise from the glottis, i.e. the true vocal cord, and are usually squamous cell carcinomas. Three-quarters of these patients present early, i.e. without vocal cord fixation, nodal involvement or extension beyond the larynx (Groome 2001; Joslin 1995; Robin 1989; Shah 1997). Reported fiveyear survival rates following treatment of these early tumours, adjusted for deaths from other causes, frequently exceed $85 \%$ (Groome 2001; Joslin 1995; Robin 1989; Shah 1997).

\section{Description of the intervention}

Radiotherapy, open surgery and endolaryngeal excision are all accepted modalities of treatment for early-stage glottic cancer (T1-T2, N0). Radiotherapy utilises ionising radiation to initiate double-stranded breaks of nuclear DNA leading to loss of the cells' reproductive ability and eventually to cell death. Radiotherapy offers laryngeal preservation, however it is a prolonged treatment course and may be associated with unpleasant adverse effects including oral mucositis, dysphagia, radiation skin burns and xerostomia. Open laryngeal surgery involves an open neck wound with partial or total surgical resection of the larynx with insertion of an indwelling voice prosthesis to allow speech in cases of total laryngectomy, although total laryngectomy is rarely indicated for early-stage cancers. Endolaryngeal surgery is minimally invasive in comparison and involves resection of the tumour via the transoral route with or without the use of laser, with the advantages of preservation of voice and laryngeal function.

\section{Why it is important to do this review}

When this review was originally written in 2002, early laryngeal tumours were largely treated with open surgery or radiotherapy, with results of case series demonstrating similar survival rates. Radiotherapy offers the advantage of voice preservation over open surgery, therefore it was previously the generally preferred treatment modality (Groome 2001; Mendenhall 1994; O'Sullivan 1994; Shah 1997; Stalpers 1989). However, open surgery remained an option, particularly in populations without access to specialist centres for radiotherapy.

In recent years endolaryngeal surgery (with or without laser) has grown in popularity (DAHNO 2012), and there has been an observed trend away from open surgery as a result. Endolaryngeal surgery offers survival rates that are similar to radiotherapy and has an advantage over open surgery in preservation of voice and laryngeal function. A number of systematic reviews of nonrandomised studies have been undertaken (Abdurehim 2011; Feng 2011; Higgins 2009; Spielmann 2010), all of which have failed to demonstrate a significant difference between survival rates after radiotherapy or endolaryngeal surgery. Voice outcomes may also be similar following radiotherapy and endolaryngeal surgery (Cohen 2006; Hirano 1985; Keilmann 1996; McGuirt 1994; Sittel 1998), thus creating a position of equipoise between these two treatment modalities.

Endolaryngeal resection requires access to specialist surgeons with appropriate experience and expertise, however recent years have seen an apparent increase in the use of this modality of treatment (Hoffman 2006). For example, in England and Wales it has been reported that patients are as likely to receive transoral laser-assisted microsurgical resection as they are to receive radiotherapy (Bradley 2009; DAHNO 2012), although there remains a geographical discrepancy as some UK centres still do not offer transoral laser surgery (DAHNO 2012).

If recurrence does occur, the options for further treatment after endolaryngeal surgery not only include open surgery but also further endolaryngeal resection and radiotherapy, whereas locoregional failure after radiotherapy can only be treated with major open surgical intervention (Goh 1996; Jensen 1994; Smee 2000). Additionally, as endolaryngeal resection is often a day-case procedure, some clinicians believe that treatment costs will be less than for radiotherapy (Brandenburg 2001; Goor 2007); this is supported by a recent cost-utility analysis (Higgins 2011).

Therapeutic conflicts in the management of early laryngeal cancers are sustained by the belief that randomised controlled trials have not been and could not be undertaken (Goh 1996). We have undertaken a systematic review to identify any randomised controlled trials comparing open surgery, radiotherapy and endolaryngeal excision in patients with early glottic cancer.

\section{O B JECT IVES}

To compare the effectiveness of open surgery, endolaryngeal excision (with or without laser) and radiotherapy in the management of early glottic laryngeal cancer.

\section{METHODS}

\section{Criteria for considering studies for this review \\ Types of studies}

We included randomised controlled trials that compared open surgery, endolaryngeal resection and/or radiotherapy. We did not consider trials which compared different radiotherapeutic techniques. We also excluded trials which were primarily a comparison of treatments for advanced laryngeal cancer. We only included trials with a radiotherapy arm when patients were predominantly recruited from 1980 onwards, because of concerns that regimens prior to that date may have been sub-optimal.

\section{Types of participants}

The study population was limited to patients diagnosed with early squamous cell carcinoma of the glottic larynx following laryngoscopy and biopsy. Early-stage tumours were defined as carcinoma in situ (Tis) or invasive cancers confined to the vocal cords or with supraglottic or subglottic extension without cord fixation or nodal metastases (T1-T2, N0) (Sobin 1997). 


\section{Types of interventions}

Open surgery, endolaryngeal excision (with or without laser) and/ or radiotherapy.

\section{Types of outcome measures}

\section{Primary outcomes}

We compared different modalities of treatment using the following primary outcome measure:

- Mortality - survival at five years.

\section{Secondary outcomes}

- Morbidity - post-treatment complications (bleeding, mucositis, swallowing dysfunction, weight loss), immediate and delayed.

- Voice quality - at one year.

- Recurrence of disease - at five years.

- Quality of life - at one year.

- Cost.

\section{Search methods for identification of studies}

We conducted systematic searches for randomised controlled trials. There were no language, publication year or publication status restrictions. The date of the most recent search was 18 September 2014, following previous searches in November 2013, February 2013, 2012, 2009, 2007, 2006, 2003 and 2000.

\section{Electronic searches}

We searched the following databases from their inception for published, unpublished and ongoing trials: the Cochrane Ear, Nose and Throat Disorders Group Trials Register; the Cochrane Central Register of Controlled Trials (CENTRAL 2014, Issue 8); PubMed; EMBASE; CINAHL; LILACS; KoreaMed; IndMed; PakMediNet; CAB Abstracts; Web of Science; ClinicalTrials.gov; ICTRP; Google Scholar and Google. In searches prior to 2013, we also searched BIOSIS Previews 1926 to 2012, ISRCTN and CNKI.

We modelled subject strategies for databases on the search strategy designed for CENTRAL. Where appropriate, we combined subject strategies with adaptations of the highly sensitive search strategy designed by The Cochrane Collaboration for identifying randomised controlled trials and controlled clinical trials (as described in theCochrane Handbook for Systematic Reviews of Interventions Version 5.1.0, Box 6.4.b. (Handbook 2011)). Search strategies for major databases including CENTRAL are provided in Appendix 1.

\section{Searching other resources}

We scanned the reference lists of retrieved review articles to identify other trials and wrote to a number of researchers who had published in this area. We handsearched the Proceedings of the 2nd World Congress on Laryngeal Cancer and the 5th International Conference for Head and Neck Cancer for abstracts of, and references to, other relevant studies.

\section{Data collection and analysis}

\section{Selection of studies}

One author performed the searches and two authors reviewed the abstracts. We requested and translated manuscripts of potentially relevant studies whenever necessary. Laura Warner (LW) and Paola Dey (PD) reviewed relevant manuscripts to identify reports of randomised controlled trials comparing the interventions of interest in patients with early-stage laryngeal cancer. When randomised controlled trials were identified we obscured information which could identify the journal of publication, authors' names and their affiliation before the manuscripts were independently assessed by two further authors (Kenneth McKenzie (KMacK) and Richard Wight (RW)) to determine eligibility for inclusion in the review and methodological quality.

\section{Data extraction and management}

Two authors used a data extraction form adapted from the proforma designed by the Cochrane Musculoskeletal Injuries Group to extract data and assess risk of bias. PD contacted the authors of the included trial for additional information.

\section{Assessment of risk of bias in included studies}

LW and PD undertook assessment of the risk of bias of the included trials independently, with the following taken into consideration, as guided by theCochrane Handbook for Systematic Reviews of Interventions (Handbook 2011):

- sequence generation;

- allocation concealment;

- blinding;

- incomplete outcome data;

- selective outcome reporting; and

- other sources of bias.

We used the Cochrane 'Risk of bias' tool in RevMan 5.3 (RevMan 2014), which involves describing each of these domains as reported in the trial and then assigning a judgement about the adequacy of each entry: 'low', 'high' or 'unclear' risk of bias. We reported these judgements in a 'Risk of bias' table.

\section{Data synthesis}

If there are sufficient data available from trials of comparable interventions and outcomes in future updates of this review, we will pool data in a meta-analysis for each outcome for the following comparisons:

- radiotherapy with surgery;

- surgery with transoral laser surgery;

- radiotherapy with transoral laser surgery.

We will assess statistical heterogeneity using the $\mathrm{I}^{2}$ statistic. We will use Peto odds ratios with $95 \%$ confidence intervals to summarise five-year overall and disease-free survival and other dichotomous variables. We will use standardised mean differences (SMD) when pooling continuous data from comparable measures. If data are available, we may undertake subgroup analysis for different tumour stages.

Radiotherapy versus open surgery versus endolaryngeal surgery (with or without laser) for early laryngeal squamous cell cancer 


\section{RESULTS}

\section{Description of studies}

\section{Results of the search}

The most recent update search in September 2014 identified 450 records, the previous search in November 2013 identified 469 records and the search in February 2013 identified 1010 records, however no new published randomised controlled trials were identified (Figure 1). In the 2014 update, we also confirmed that one study remains ongoing (Saedi 2007) (see Characteristics of ongoing studies). Other trials which we had previously identified as ongoing have either now been abandoned (Abdurehim 2009; EaStER 2006), or there was no response from the authors when contacted (Coman 2003). The EaStER feasibility randomised trial comparing the effectiveness of radiotherapy and endoscopic excision (with or without laser) is closed and recruited only 17 patients to the trial, however the patients were reported as being followed up, so the status is unknown (EaStER 2006) (see Characteristics of studies awaiting classification). 
Figure 1. Study flow diagram.

\section{1 study included in previously published review}

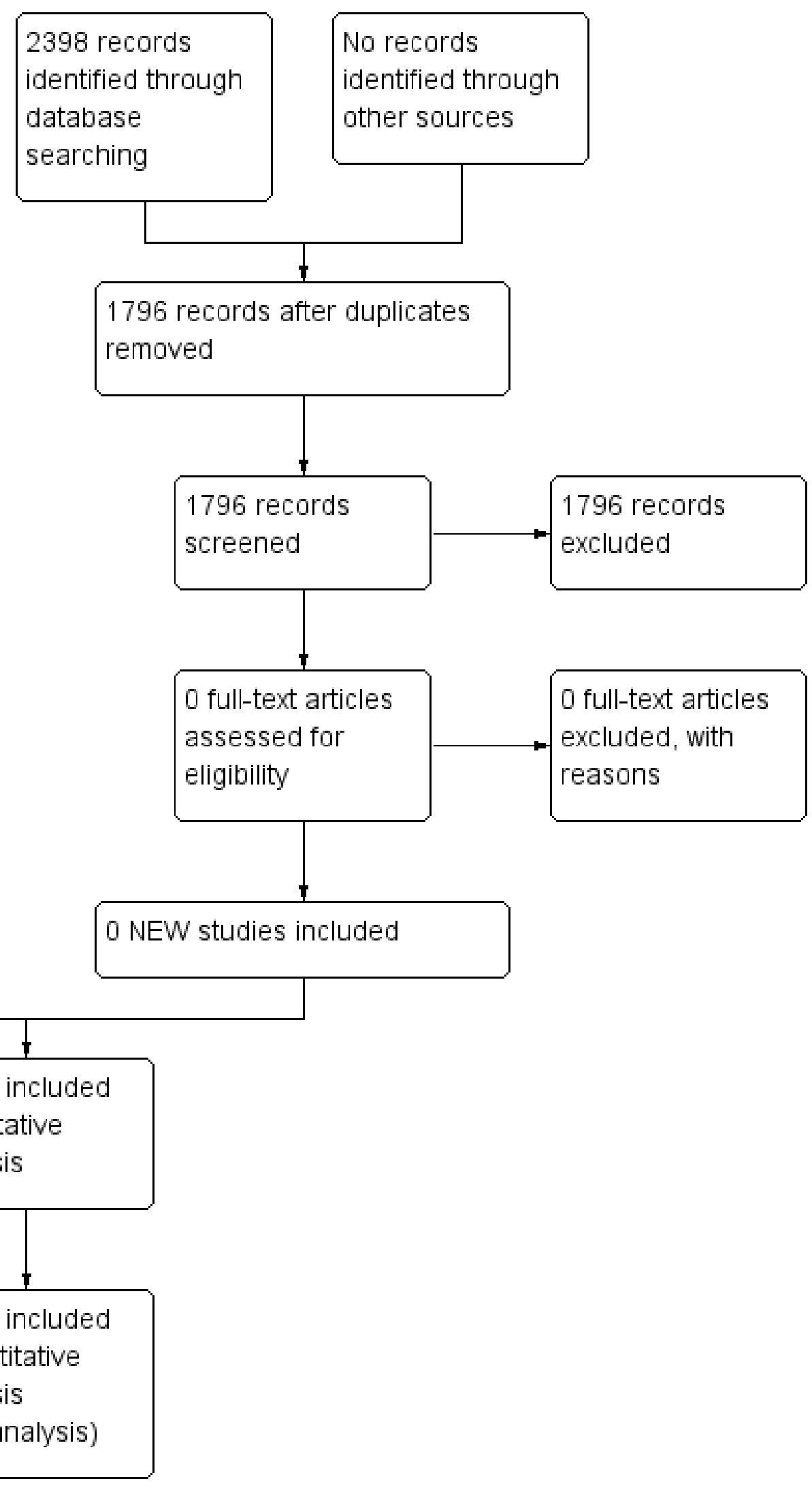


A total of 962 abstracts had been reviewed following the update searches covering the period 2000 to October 2009. The original searches for the review identified 455 abstracts. From the combined searches we identified four possible randomised controlled trials comparing surgery and radiotherapy. We excluded three of these, with reasons (Hintz 1979; Li 1993; Yin 2000), and we included one trial in the review (Ogoltsova 1990). We identified no randomised controlled trials including endolaryngeal surgery.

\section{Included studies}

\section{See Characteristics of included studies.}

Only one trial recruited a substantial number of patients with glottic cancer; this was a multicentre randomised controlled trial undertaken in Eastern Europe, that is the former Soviet Union, Hungary and Czechoslovakia (Ogoltsova 1990). Patients were recruited from 1979 and randomised to open surgery, radiotherapy or a combination of radiotherapy and chemotherapy after stratification by anatomical site (glottis or supraglottis) and tumour stage ( $\mathrm{T} 1$ or $\mathrm{T} 2$ ). Two hundred and sixty-nine patients were evaluated, of whom 234 had glottic laryngeal cancer. Patients were followed up for five years and recurrence-free and survival rates were reported.

\section{Excluded studies}

\section{See Characteristics of excluded studies.}

Hintz et al reported the results of a randomised controlled trial involving 108 head and neck patients. We excluded this trial because of the small number of eligible patients who were recruited between 1971 and 1976. Seventy-five patients were available for analysis of whom only 24 had early stage glottic cancer; staging was retrospective. Patients were not stratified by site or stage before randomisation and of eight patients with $\mathrm{T} 2$ glottic cancer only one received surgery. Analysis was not on an intention-to-treat basis. The authors suggest that radiotherapy dosimetry may have been sub-optimal (Hintz 1979).

We excluded one trial immediately after translation; this randomised controlled trial reported on the efficacy of preoperative radiotherapy and only 14 patients with early glottic laryngeal cancer were randomised to surgery alone (Li 1993).

We excluded a further trial because it assessed the effectiveness of postoperative radiotherapy, and the stage of disease was not clearly defined (Yin 2000).

Abdurehim 2009, which we had previously identified as an ongoing study, has now been abandoned due to difficulty recruiting patients.

\section{Risk of bias in included studies}

We had a number of concerns about the methodology of the included study (Ogoltsova 1990), and we originally gave it a 'grade $C^{\prime}$ quality rating. At the 2014 update, using the Cochrane 'Risk of bias' tool, we judged it to be at high risk of bias.

\section{Allocation}

Randomisation was by consecutive numbers, which were implemented in each co-operative centre by "converters", but it is not clear whether the randomisation schedule was concealed from the investigators. The total number of patients randomised to each treatment arm is not provided and data are not available on the baseline characteristics of treatment groups at study entry. The number of patients evaluated in each group is unbalanced; 76 were allocated surgery but 129 allocated radiotherapy. A further 64 evaluable patients were allocated combination therapy, that is radiotherapy and chemotherapy; these patients are not further considered in this review. There is no evidence that the trial was designed with 2:1 allocation, but the authors do admit that followup was poor and therefore the imbalance may be due to differential follow-up.

\section{Blinding}

Outcomes were not assessed blind and no detail is provided on how and when outcome assessment was performed.

\section{Incomplete outcome data}

There were difficulties with the completion of follow-up and loss of patients to follow-up during the study is mentioned.

\section{Selective reporting}

The number of patients with glottic cancer evaluated in each arm is not provided. The number of patients in each arm available for outcome evaluation at specified time points is not available.

\section{Other potential sources of bias}

The method of diagnosis and preoperative staging is not detailed, but the investigators suggest that patients had been inadequately staged before treatment. The authors were concerned that surgical interventions had not been standardised and that radiotherapy regimens may be sub-optimal; patients received gamma irradiation suggesting the use of cobalt units and neither treatment volume nor technique are reported.

Survival is compared using a Mantel-Haenszel test and the $\mathrm{Chi}^{2}$ statistic at 1 degree of freedom is reported at the one-sided $5 \%$ significance level.

\section{Effects of interventions}

One study is included in the review (Ogoltsova 1990).

\section{Primary outcome}

\section{Mortality - survival at five years}

Five-year survival rates are presented for each tumour stage (T1 and T2) for patients with glottic cancer. The number of events and the number of patients at risk in each arm at each specified time point are not presented. For T1 tumours, the five-year survival was $91.7 \%$ following radiotherapy and $100 \%$ following surgery and for T2 tumours, $88.8 \%$ following radiotherapy and $97.4 \%$ following surgery. There were no significant differences in survival between the two groups.

\section{Secondary outcomes}

Morbidity - post-treatment complications (bleeding, mucositis, swallowing dysfunction, weight loss), immediate and delayed

No data were available for this outcome. 


\section{Voice quality - at one year}

No data were available for this outcome.

\section{Recurrence of disease - at five years}

Five-year locoregional recurrence rates are presented for each tumour stage for patients with glottic cancer. Again the number of events and the number of patients at risk in each arm at each specified time point are not presented. There is some inconsistency in the text regarding the number of locoregional recurrences in the whole group. For T1 tumours, the five-year disease-free survival rate was $71.1 \%$ following radiotherapy and $100.0 \%$ following surgery, and for the T2 tumours, $60.1 \%$ following radiotherapy and $78.7 \%$ following surgery. Only the latter comparison is statistically significant (Chi $1.8, \mathrm{P}$ value $=0.036$ ), but statistical significance would not have been achieved with a two-sided test.

\section{Quality of life - at one year}

No data were available for this outcome.

Cost

No data were available for this outcome.

\section{DISCUSSION}

\section{Summary of main results}

There is no good evidence available from randomised controlled trials to guide treatment choice for patients with early-stage glottic cancer.

\section{Quality of the evidence}

Interpretation of the findings of the only randomised controlled trial that recruited substantial numbers of patients to a comparison between radiotherapy and open surgery is limited by concerns about the adequacy of treatment regimens and deficiencies in the reporting of the study design and analysis. In this trial, open surgical outcomes were better than might be expected from data derived from case series whilst radiotherapy outcomes were worse. The trial investigators admitted that patients were inadequately staged prior to therapy, and radiotherapy may have been suboptimal. In addition, follow-up was poor and differences between groups may be biased by differential follow-up.

There are no published randomised controlled trials comparing the effectiveness of endolaryngeal resection with either radiotherapy or open surgery and difficulties in recruiting and randomising patients with early laryngeal cancers has been noted by authors of abandoned studies. The difficulties in recruiting to the EaStER trial are addressed in a paper by Hamilton et al, who describe a difference in surgeons' and recruiters' opinions of optimum treatment of carcinoma in situ and those tumours involving the anterior commissure. Additionally, the recruiters felt that there was non-equivalence of the treatment process as endolaryngeal surgery was often considered by patients and clinicians to be more convenient compared to radiotherapy and therefore consent to randomisation was not given (Hamilton 2013).

\section{Potential biases in the review process}

At the 2014 update, using the Cochrane 'Risk of bias' method, we judged the included study to be at high risk of bias (Ogoltsova 1990).

\section{Agreements and disagreements with other studies or reviews}

Our recent search has identified five systematic reviews comparing endolaryngeal surgery and radiotherapy published since 2009 (Abdurehim 2011; Feng 2011; Higgins 2009; Spielmann 2010; Yoo 2013). None identified any randomised trials and they varied in staging criteria, types of study (comparative only or case series and comparative studies) and outcomes for study inclusion. Those including comparative studies only suggest similar oncological and functional outcomes (Abdurehim 2011; Feng 2011; Spielmann 2010; Yoo 2013).

Several studies have reported use of concomitant chemoradiotherapy in the treatment of $\mathrm{T} 2$ laryngeal cancers (Niibe 2007; Ohguri 2008). The results show promising local control rates, particularly when combined with debulking transoral laser surgery. In years to come concomitant chemoradiotherapy may gain popularity as it offers organ preservation with improved local control rates. The efficacy of this new approach will need to be further elucidated.

\section{AUTHORS' CONCLUSIONS}

\section{Implications for practice}

Based on the results of one randomised controlled trial, there remains uncertainty as to the comparative benefits and societal costs of different treatment modalities for patients with early glottic laryngeal cancer. Using the Cochrane 'Risk of bias' method we judged this study to have a high risk of bias.

Endolaryngeal surgery is gaining popularity in the management of early laryngeal tumours due to voice preservation, shorter treatment duration and results from case series, which show similar survival rates to radiotherapy (Csanady 1995; Eckel 2001; Mahieu 2000; Mendenhall 2004; Motta 1997; Ossoff 1985; Steiner 1993; Wolfensberger 1990; Zeitels 1996). Like radiotherapy, endolaryngeal resection is voice-sparing and the shorter treatment duration may further benefit patients and lead to resource savings. In Western countries, where open surgery is infrequently performed, endolaryngeal resection is becoming more popular. A consensus document on behalf of the ENT-UK Head and Neck Group reported that endoscopic excision is now generally the preferred treatment option, particularly for T1a tumours, and suggested that endolaryngeal surgery should be offered to all patients with early laryngeal tumours up to stage 2a (Bradley 2009). As experience with endolaryngeal surgery increases, the application of this treatment modality is expanding to involve more extensive laryngeal tumours, although radiotherapy may offer preferable vocal outcomes when extensive cordectomy is required (Silver 2009). Furthermore, treatment of the anterior commissure remains controversial as local recurrence rates and vocal outcomes after transoral laser assisted surgery are worse when the anterior commissure is involved and radiotherapy is therefore often preferred in this subset of patients (Chone 2007; Hakeem 2013; Sachse 2009).

\section{Implications for research}

Most patients diagnosed with early laryngeal cancer in Western countries are now treated with either radiotherapy or endolaryngeal surgery. A number of workers consider that it is unlikely that randomised controlled trials comparing open surgery

Radiotherapy versus open surgery versus endolaryngeal surgery (with or without laser) for early laryngeal squamous cell cancer 
and radiotherapy can be undertaken, because so many clinicians believe that the three treatment modalities confer similar survival advantage but that voice outcomes after open surgery are worse. However, the continued publication of non-randomised studies suggests that even in the West there remains some controversy as to the most cost-effective treatment (Groome 2001). This systematic review demonstrates that a randomised controlled trial comparing radiotherapy and open surgery has been undertaken (Ogoltsova 1990), however its conclusions are compromised by methodological and analytical deficiencies.

We identified two recent trials and two protocols for studies. The EaStER feasibility randomised trial (EaStER 2006), comparing the effectiveness of radiotherapy and endoscopic excision (with or without laser), is closed and recruited only 17 patients. The status of the other randomised controlled trial that recruited participants is unknown (Coman 2003). One randomised trial was abandoned due to difficulty in recruiting patients (Abdurehim 2009), and one further study is ongoing (Saedi 2007).

A paper by Hamilton et al details the specific difficulties in recruiting patients to the EaStER trial (Hamilton 2013). The authors describe how surgeons and recruiters felt there was a lack of equipoise between the two treatment options, as endolaryngeal surgery was considered to be more convenient, meaning that recruitment discussions focused on the treatment process rather than expected outcomes. Furthermore, whilst endolaryngeal surgery is generally preferred for T1a cancers, particularly mid-cord lesions, radiotherapy is preferred for anterior commissure lesions, thus the anatomical location of the tumour may create bias when considering recruiting patients to a trial.

Although difficulties have been encountered in recruiting patients to randomised controlled trials, it remains vitally important that randomised studies are undertaken in this field. As data from non-randomised series have demonstrated similar oncological outcomes between radiotherapy and endolaryngeal surgery, quality of life and vocal outcome data must be studied.

\section{ACKN OWLEDGEMENTS}

Janet Wilson, Professor of Otolaryngology, Head and Neck Surgery, Freeman Hospital, who helped to initiate the study and applied for funding and was previously a co-author. Derrick Arnold, former data manager for the centre of cancer epidemiology, Christie Hospital NHS trust, who was involved in the original search. Melanie Hinde, formerly Medical Librarian, Christie Hospital NHS Trust Medical Library, for her invaluable help and advice on search strategies and for conducting additional searches. 


\section{RE F E R E N C E S}

\section{References to studies included in this review}

Ogoltsova 1990 \{published data only\}

Ogoltsova ES, Paches AI, Matiakin EG, Dvoírin VV, Fedotenko SP, Alferov VS, et al. Comparative evaluation of the efficacy of radiotherapy, surgery and combined treatment of stage IIl laryngeal cancer (T1-2N0M0) on the basis of co-operative studies. Vestnik Otorinolaringologii 1990;3:3-7.

\section{References to studies excluded from this review}

\section{Abdurehim 2009 \{unpublished data only\}}

Abdurehim Y. Radiotherapy versus endolaryngeal laser resection for early stage glottic cancer: a randomized controlled trial. Chinese Clinical Trial Registry 2009 (accessed 2 June 2010). [ChiCTR-TRC-00000362]

\section{Hintz 1979 \{published data only\}}

Hintz B, Charyulu K, Chandler JR, Sudarsanam A, Garciga C. Randomized study of local control and survival following radical surgery or radiation therapy in oral and laryngeal carcinomas. Journal of Surgical Oncology 1979;12:61-74.

\section{Li 1993 \{published data only\}}

Li GZ. A comparison of the therapeutic effect between preoperative radiotherapy plus operation and operation alone for laryngocarcinoma. A prospective study of 260 cases. Chung Hua Erh Pi Yen Hou Ko Tsa Chih 1993;28(3):170-3.

Yin 2000 \{published data only\}

* Yin ZP. Surgery plus postoperative radiation vs operation alone for glottic carcinoma. 2000 International and 6th National Head and Neck Cancer Conference. 2000:160.

Yin ZP. Surgery plus postoperative radiation vs operation alone for glottic carcinoma. Journal of Henan Oncology 2001;14(3):184-5.

\section{References to studies awaiting assessment}

\section{Coman 2003 \{unpublished data only\}}

Coman WB, Hendrikz JK, Hickey B, Cahill L, Hancock K, Dutkowski K, et al. Laser surgery for early glottic cancer. Royal Australasian College of Surgeons Annual Scientific Congress, Brisbane 5-9, May 2003, Abstract No. HN14 (http:// www.blackwellpublishing.com). 2003.

\section{EaStER 2006 \{published data only\}}

Birchall M. EaStER - Early stage glottic cancer: endoscopic excision or radiotherapy: a feasibility study. http:// www.controlled-trials.com/ISRCTN17541410 2007 (accessed 2 June 2010). [ISRCTN17541410; NCT00334997]

\section{References to ongoing studies}

Saedi 2007 \{published data only\}

Saedi B. The comparison of voice quality in early laryngeal cancer between surgery and radiotherapy. http://
clinicaltrials.gov/ct2/show/NCT00497588 2007 (accessed 2 June 2010). [NCT00497588]

\section{Additional references}

Abdurehim 2011

Abdurehim Y, Hua Z, Yasin Y, Xukurhan A, Imam I, Yuqin F. Transoral laser surgery versus radiotherapy: systematic review and meta-analysis for treatment options of T1a glottic cancer. Head and Neck 2011;34(1):23-33

\section{Bradley 2009}

Bradley PJ, Mackenzie K, Wright R, Pracy P, Paleri V. Consensus statement on management in the UK: transoral laser assisted microsurgical resection of early glottic cancer. Clinical Otolaryngology 2009;34:367-73.

\section{Brandenburg 2001}

Brandenburg JH. Laser cordotomy versus radiotherapy: an objective cost analysis. Annals of Otology, Rhinology and Laryngology 2001;110:312-8.

\section{Chone 2007}

Chone C, Yonehara E, Martins J, Altemani A, Crespo A. Importance of anterior commissure in recurrence of early glottic cancer after laser endoscopic resection. Archives of Otolaryngology -- Head and Neck Surgery 2007;133(9):882-7.

\section{Cohen 2006}

Cohen SM, Garrett G, Dupont WD, Ossoff RH, Courey MS. Voice-related quality of life in T1 glottic cancer: irradiation versus endoscopic excision. Annals of Otology, Rhinology and Laryngology 2006;115(8):581-6.

\section{Coleman 1993}

Coleman MP, Esteve J, Damiecki P, Arslan A, Renard H (editors) Trends in Cancer Incidence and Mortality. Lyon: IARC Scientific Publications No 121, 1993.

\section{Csanady 1995}

Csanady M, Czigner J, Savay L. Endolaryngeal CO2 laser microsurgery of early vocal cord cancer. A retrospective study. Advances in Otorhinolaryngology 1995;49:219-21.

\section{DAHNO 2012}

National Head and Neck Cancer Audit 2012. http:// www.hscic.gov.uk/catalogue/PUB11015/clin-audi-supp-proghead-neck-dahn-11-12-rep0.pdf 2012.

\section{Eckel 2001}

Eckel HE. Local recurrences following transoral laser surgery for early glottic carcinoma: frequency, management, and outcome. Annals of Otology, Rhinology and Laryngology 2001;110:7-15.

\section{Feng 2011}

Feng Y, Wang B, Wen S. Laser surgery versus radiotherapy for T1-T2N0 glottic cancer: a meta-analysis. ORL; Journal of OtoRhino-Laryngology and Its Related Specialties 2011;73:336-42.

Radiotherapy versus open surgery versus endolaryngeal surgery (with or without laser) for early laryngeal squamous cell cancer 


\section{GLOBOCAN 2012}

Ferlay J, Soerjomataram I, Ervik M, Dikshit R, Eser S, Mathers C, et al. GLOBOCAN 2012 v1.0, Cancer Incidence and Mortality Worldwide: IARC CancerBase No. 11. Lyon, France: International Agency for Research on Cancer (available from http:// globocan.iarc.fr) 2013 (accessed 12 September 2014).

\section{Goh 1996}

Goh C, O'Sullivan B, Warde P, Groome P, Gullane P. Multidisciplinary management controversies in laryngeal cancer. Annals of the Academy of Medicine Singapore 1996;25(3):405-12

\section{Goor 2007}

Goor KM, Peeters AJ, Mahieu HF, Langendijk JA, Leemans CR, Verdonck-de Leeuw IM, et al. Cordectomy by CO2 laser or radiotherapy for small T1a glottic carcinomas: costs, local control, survival, quality of life, and voice quality. Head and Neck 2007;29(2):128-36.

\section{Groome 2001}

Groome PA, O'Sullivan B, Irish JC, Rothwell DM, Math KS, Bissett RJ, et al. Glottic cancer in Ontario, Canada and the SEER areas of the United States: do different management philosophies produce different outcome profiles?. Journal of Clinical Epidemiology 2001;54:301-15.

\section{Hakeem 2013}

Hakeem A, Tubchi J, Pradham S. Significance of anterior commissure involvement in early glottic squamous cell carcinoma treated with trans-oral $\mathrm{CO} 2$ laser microsurgery. Laryngoscope 2013;123(8):1912-7.

\section{Hamilton 2013}

Hamilton DW, de Salis I, Donovan Jl, Birchall M. The recruitment of patients to trials in head and neck cancer:a qualitative study of the EaStER trial of treatments for early laryngeal cancer. European Archives of Oto-Rhino-Laryngology 2013;270(8):2333-7.

\section{Handbook 2011}

Higgins JPT, Green S (editors). Cochrane Handbook for Systematic Reviews of Interventions Version 5.1.0 [updated March 2011]. The Cochrane Collaboration, 2011. Available from www.cochrane-handbook.org.

\section{Higgins 2009}

Higgins K, Shah M, Ogaick M, Enepekides D. Treatment of earlystage glottic cancer: meta-analysis comparison of laser excision versus radiotherapy. Journal of Otolaryngology, Head and Neck Surgery 2009;38:603-12.

\section{Higgins 2011}

Higgins KM. What treatment for early-stage glottic carcinoma among adult patients: $\mathrm{CO} 2$ endolaryngeal laser excision versus standard fractionated external beam radiation is superior in terms of cost utility?. Laryngoscope 2011;121:116-34.

\section{Hirano 1985}

Hirano M, Hirade Y, Kawasaki H. Vocal function following carbon dioxide laser surgery for glottic carcinoma. Annals of Otology, Rhinology and Laryngology 1985;94(3):232-5.

\section{Hoffman 2006}

Hoffman HT, Porter K, Karnell LH, Cooper JS, Weber RS, Langer CJ, et al. Laryngeal cancer in the United States: changes in demographics, patterns of care, and survival. Laryngoscope 2006;116(9):1529.

\section{Jensen 1994}

Jensen AB, Hansen O, Jorgensen K, Bastholt L. Influence of late side effects upon daily life after radiotherapy for laryngeal and pharyngeal cancer. Acta Oncologica 1994;33(5):487-91.

\section{Joslin 1995}

Joslin C, Rider L, Crellin A (editors). Cancers in Yorkshire. Vol. 2. Head and Neck Cancers, Yorkshire Cancer Organisation, 1995.

\section{Keilmann 1996}

Keilmann A, Bergler W, Artzt M, Hoermann K. Vocal function following laser and conventional surgery of small malignant vocal fold tumours. Journal of Laryngology and Otology 1996;110(12):1138-41.

\section{Mahieu 2000}

Mahieu H, Peeters J, Snel F, Leemans R. Transoral endoscopic surgery for early glottic cancer. 5th International Conference on Head and Neck Cancer, San Francisco. American Head and Neck Society, 2000:165-72.

\section{McGuirt 1994}

McGuirt WF, Blalock D, Koufman JA, Feehs RS, Hilliard AJ, Greven $\mathrm{K}$, et al. Comparative voice results after laser resection or irradiation of T1 vocal cord carcinoma. Archives of Otolaryngology - Head and Neck Surgery 1994;120:951-5.

\section{Mendenhall 1994}

Mendenhall WM, Parsons JT, Stringer SP, Cassisi NJ. Management of Tis, T1 and T2 squamous cell carcinoma of the glottic larynx. American Journal of Otolaryngology 1994;15(4):250-7.

\section{Mendenhall 2004}

Mendenhall WM, Werning JW, Hinerman RW, Amdur RJ, Villaret DB. Management of T1-T2 glottic carcinomas. Cancer 2004;100:1786-92.

\section{Motta 1997}

Motta G, Esposito E, Cassiano B, Motta S. T1-T2-T3 glottic tumours: fifteen years experience with $\mathrm{CO} 2$ laser. Acta Otolaryngologica (Stockholm) 1997;Suppl 527:155-9.

\section{Niibe 2007}

Niibe Y, Nakayama M, Matsubayashi T, Takahashi H, Kitano M, Okamoto M, et al. Effectiveness of concurrent radiation therapy with UFT or TS-1 for T2N0 glottic cancer in Japan. Anticancer Research 2007;27:3497-500. 


\section{O'Sullivan 1994}

O'Sullivan B, Mackillop W, Gilbert R, Gaze M, Lundgren J, Atkinson $\mathrm{C}$, et al. Controversies in the management of laryngeal cancer: results of an international survey of patterns of care. Radiotherapy and Oncology 1994;31(1):23-32.

\section{Ohguri 2008}

Ohguri T, Imada H, Nakano K, Yahara K, Udaka T, Suzuki H, et al. Concurrent hyperfractionated radiotherapy and carboplatin with transoral debulking microsurgery for T2N0 glottic cancer. Head and Neck 2008;30:1027-34.

\section{Ossoff 1985}

Ossoff RH, Sisson GA, Shapshay SM. Endoscopic management of selected early vocal cord carcinoma. Annals of Otology, Rhinology and Laryngology 1985;94:560-4.

\section{Parkin 1997}

Parkin DM, Whelan SL, Ferlay J, Storm H (editors). Cancer Incidence in Five Continents. Vol. VII, Lyon: IARC Scientific Publications No 143, 1997.

\section{RevMan 2014 [Computer program]}

The Nordic Cochrane Centre, The Cochrane Collaboration. Review Manager (RevMan). Version 5.3. Copenhagen: The Nordic Cochrane Centre, The Cochrane Collaboration, 2014.

\section{Robin 1989}

Robin PE, Powell J, Holme GM (editors). Clinical Cancer Monographs. 2. Cancer of the Larynx. Southampton: Macmillan, 1989.

\section{Sachse 2009}

Sachse F, Stoll W, Rudack C. Evaluation of treatment results with regard to initial anterior commissure involvement in early glottic carcinoma treated by external partial surgery or transoral laser microresection. Head and Neck 2009;31(4):531-7.

\section{Shah 1997}

Shah JP, Karnell LH, Hoffman HT, Ariyan S, Brown GS, Fee WE, et al. Patterns of care for cancer of the larynx in the United States. Archives of Otolaryngology - Head and Neck Surgery 1997;123(5):475-83.

\section{Silver 2009}

Silver C, Beitler J, Shaha A, Rinaldo A, Ferlito A. Current trends in initial management of laryngeal cancer: the declining use of open surgery. European Archives of Oto-Rhino-Laryngology 2009;266(9):1333-52.

\section{Sittel 1998}

Sittel C, Eckel HE, Eschenburg C, Vössing M, Pototschnig C, Zorowka P. Voice quality following endolaryngeal laser surgery. Laryngo-Rhino-Otologie 1998;77:219-25.

\section{CHARACTERISTICS OF STUDIES}

Characteristics of included studies [ordered by study ID]

\section{Smee 2000}

Smee R, Bridger GP, Williams J, Fisher R. Early glottic carcinoma: results of treatment by radiotherapy. Australasian Radiology 2000;44:53-9.

\section{Sobin 1997}

Sobin LH, Wittekind CH. TNM Classification of Malignant Tumours. 5th Edition. New York: John Wiley and Sons, Inc, 1997.

\section{Spielmann 2010}

Spielmann P, Majumdar S, Morton R. Quality of life and functional outcomes in the management of early glottic carcinoma: a systematic review of studies comparing radiotherapy and transoral laser microsurgery. Clinical Otolaryngology 2010;35:373-82.

\section{Stalpers 1989}

Stalpers LJA, Verbeek ALM, van Daal WAJ. Radiotherapy or surgery for T2N0M0 glottic carcinoma? A decision-analytic approach. Radiotherapy and Oncology 1989;14:209-17.

\section{Steiner 1993}

Steiner W. Results of curative laser microsurgery of laryngeal carcinomas. American Journal of Otolaryngology 1993;14(2):116-21

\section{Wolfensberger 1990}

Wolfensberger M, Dort JC. Endoscopic laser surgery for early glottic carcinoma: a clinical and experimental study. Laryngoscope 1990;100:1100-5.

\section{Yoo 2013}

Yoo J, Lachetti C, Hammond J, Gilbert R. Role of endolaryngeal surgery (with or without laser) versus radiotherapy in the management of early (T1) glottic cancer: a systematic review. Head and Neck 2013;20(2):e132-5. [DOI: 10.1002/hed.23504]

\section{Zeitels 1996}

Zeitels SM. Laser versus cold instruments for microlaryngoscopic surgery. Laryngoscope 1996;106:545-52.

\section{References to other published versions of this review Dey 2002}

Dey P, Arnold D, Wight R, Kelly CG, McKenzie K. Radiotherapy versus open surgery versus endolaryngeal surgery (with or without laser) for early laryngeal squamous cell cancer. Cochrane Database of Systematic Reviews 2002, Issue 2. [DOI: 10.1002/14651858.CD002027]

* Indicates the major publication for the study 
Ogoltsova 1990

\begin{tabular}{ll}
\hline Methods & Randomised controlled trial \\
\hline Participants & 234 patients with T1 or T2 glottic carcinoma \\
\hline Interventions & Open surgery versus radiotherapy \\
\hline Outcomes & Disease-free survival \\
& Overall survival \\
\hline Notes & Method of concealment of allocation unclear \\
& Total number of patients randomised and total number randomised to each group unclear \\
& No comparison of baseline characteristics at entry \\
& Radiotherapy regimens might be considered sub-optimal \\
& Numbers of patients at risk and number of events at specified time points not stated \\
Inconsistencies between text and tables \\
Statistical tests quoted at the one-sided 5\% level but this is not explicit in the text
\end{tabular}

\section{Risk of bias}

\begin{tabular}{lll}
\hline Bias & Authors' judgement & Support for judgement \\
\hline $\begin{array}{l}\text { Random sequence genera- } \\
\text { tion (selection bias) }\end{array}$ & High risk & $\begin{array}{l}\text { The total number of patients randomised to each treatment arm is not pro- } \\
\text { vided and data are not available on the baseline characteristics of treatment } \\
\text { groups at study entry. The number of patients evaluated in each group is un- } \\
\text { balanced. }\end{array}$
\end{tabular}

Allocation concealment Unclear risk
(selection bias)

Randomisation was by consecutive number generation, however it is not stat(selection bias) ed whether clinicians were blinded to this process. The numbers treated in each group were unbalanced and the total initially randomised to each group is not stated. Baseline characteristics between the 2 groups are not provided.

\begin{tabular}{lll}
$\begin{array}{l}\text { Blinding (performance } \\
\text { bias and detection bias) } \\
\text { All outcomes }\end{array}$ & High risk & $\begin{array}{l}\text { Blinding of treatments was not possible in this study due to the nature of treat- } \\
\text { ments }\end{array}$ \\
\hline $\begin{array}{l}\text { Incomplete outcome data } \\
\text { (attrition bias) } \\
\text { All outcomes }\end{array}$ & High risk & $\begin{array}{l}\text { Difficulties completing follow-up and loss of patients to follow-up during the } \\
\text { study is mentioned }\end{array}$ \\
\hline $\begin{array}{l}\text { Selective reporting (re- } \\
\text { porting bias) }\end{array}$ & Unclear risk & $\begin{array}{l}\text { The number of patients with glottic cancer evaluated in each arm is not pro- } \\
\text { vided. The number of patients in each arm available for outcome evaluation at } \\
\text { specified time points is not available. }\end{array}$ \\
\hline $\begin{array}{l}\text { Other bias } \\
\text { High risk }\end{array}$ & $\begin{array}{l}\text { The investigators suggest that patients may have been inadequately staged } \\
\text { before treatment. Surgical interventions were not standardised and the ra- } \\
\text { diotherapy regimens may be sub-optimal, with neither treatment volume nor } \\
\text { technique stated. }\end{array}$
\end{tabular}

Characteristics of excluded studies [ordered by study ID] 


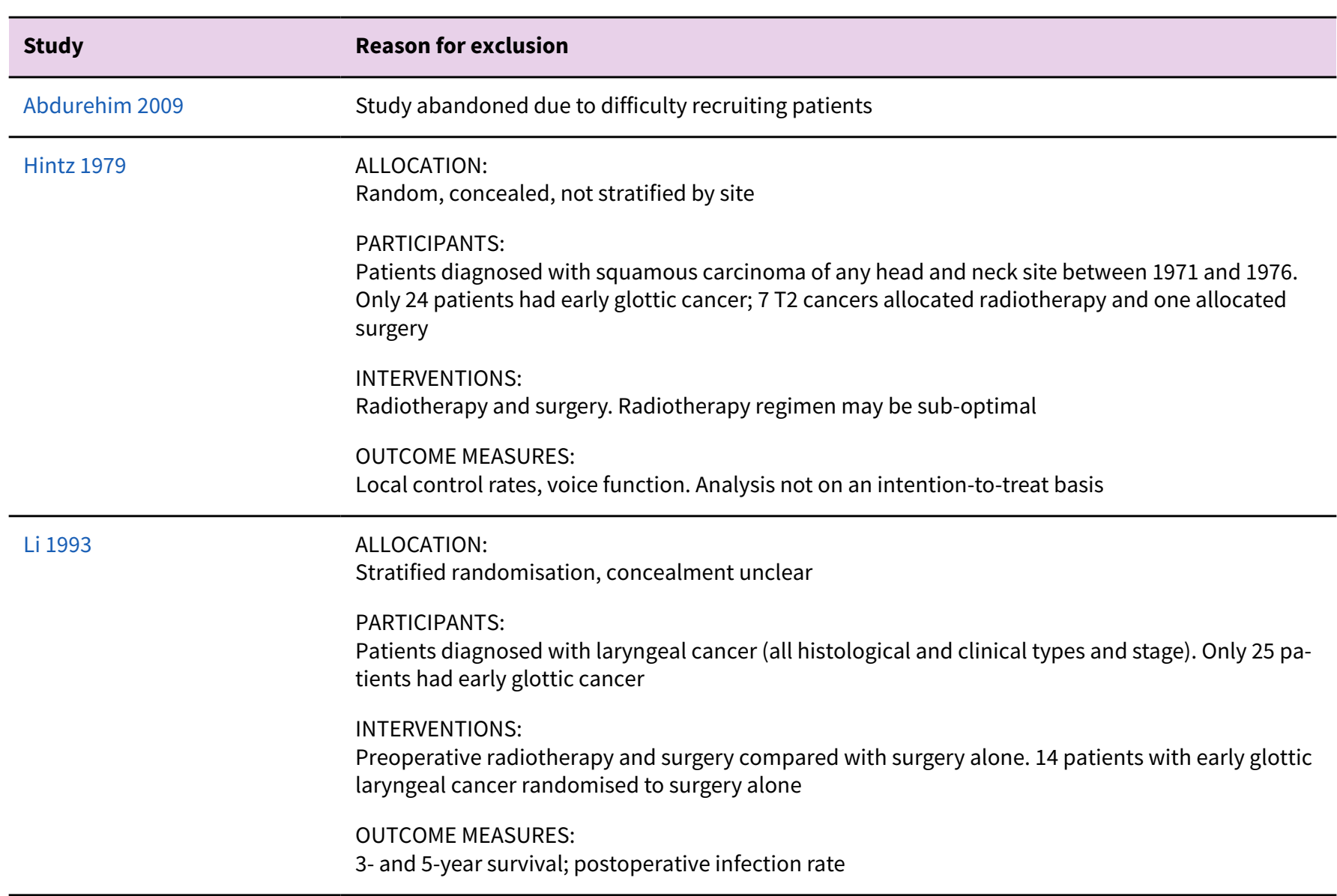

ALLOCATION:

Following surgery, method unclear, concealment unclear

PARTICIPANTS:

92 patients; stage unclear

INTERVENTIONS:

Surgery and postoperative radiotherapy compared with surgery alone

OUTCOME MEASURES:

3- and 5-year survival

Characteristics of studies awaiting assessment [ordered by study ID]

Coman 2003

\begin{tabular}{ll}
\hline Methods & Randomised controlled trial \\
\hline Participants & Patients with T1 or T2 N0 M0 glottic cancer \\
\hline Interventions & Laser surgery using CO2 laser \\
& Radiotherapy (EBRT 60 to 66 Gy for 5 days a week over 6 to 6.5 weeks) \\
\hline
\end{tabular}

Outcomes

Primary outcomes:

Local control 
Coman 2003 (Continued)

\author{
Voice quality \\ Swallowing function \\ Quality of life \\ Nutrition \\ Cost of treatment
}

Secondary outcomes:

Degree of larynx preservation

Loco-regional control

Disease-specific survival rate

Quantitative and qualitative evaluation of toxicity aspects of treatment

\title{
EaStER 2006
}

\begin{tabular}{|c|c|}
\hline Methods & Randomised controlled trial \\
\hline Participants & Patients with Tis, Tis T1 T2a NO M0 carcinoma of the glottis \\
\hline \multirow[t]{2}{*}{ Interventions } & Endoscopic excision: cold steel or laser \\
\hline & $\begin{array}{l}\text { Radiotherapy: Tis T1 non bulky tumours } 50 \text { Gy } \\
\text { T1 bulky T2a } 55 \text { Gy }\end{array}$ \\
\hline \multirow[t]{8}{*}{ Outcomes } & Primary outcome: \\
\hline & Loco-regional recurrence \\
\hline & Secondary outcomes: \\
\hline & Voice quality \\
\hline & Quality of life \\
\hline & Morbidity \\
\hline & Mortality \\
\hline & Economic assessment \\
\hline Notes & $\begin{array}{l}\text { This study is closed and recruited only } 17 \text { patients to the trial, however the patients were reported } \\
\text { as being followed up, so the status is unknown. It is said that this study has shown that endoscopic } \\
\text { excision is the preferred treatment option (Bradley 2009). }\end{array}$ \\
\hline
\end{tabular}

Characteristics of ongoing studies [ordered by study ID]

Saedi 2007

\begin{tabular}{ll}
\hline Trial name or title & The comparison of voice quality in early laryngeal cancer between surgery and radiotherapy \\
\hline Methods & Randomised, controlled, single-blind study \\
\hline Participants & Patients with early laryngeal cancer \\
\hline Interventions & Partial laryngectomy versus radiotherapy \\
\hline Outcomes & $\begin{array}{l}\text { Voice quality at } 3 \text { to } 6 \text { months } \\
\text { Quality of life at } 6 \text { months }\end{array}$ \\
\hline
\end{tabular}

Radiotherapy versus open surgery versus endolaryngeal surgery (with or without laser) for early laryngeal squamous cell cancer 
Saedi 2007 (Continued)

Starting date

March 2007

Contact information

Professor Babak Saedi, Imam Khomainee Hospital, Tehran, Iran

E-mail: saedi@tums.ac.ir

\section{AP PE N DICES}

\section{Appendix 1. Search strategies}

\begin{tabular}{|c|c|c|}
\hline CENTRAL & PubMed & EMBASE (Ovid) \\
\hline  & 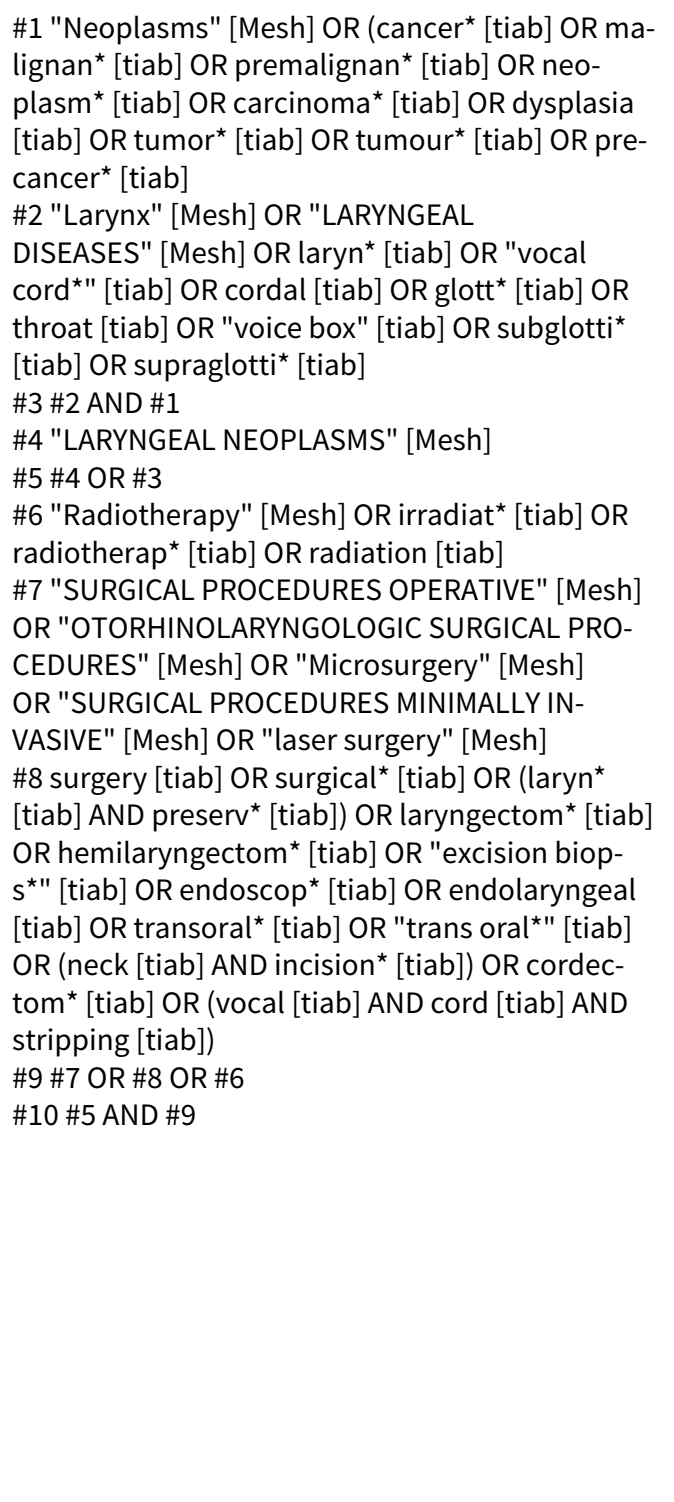 & 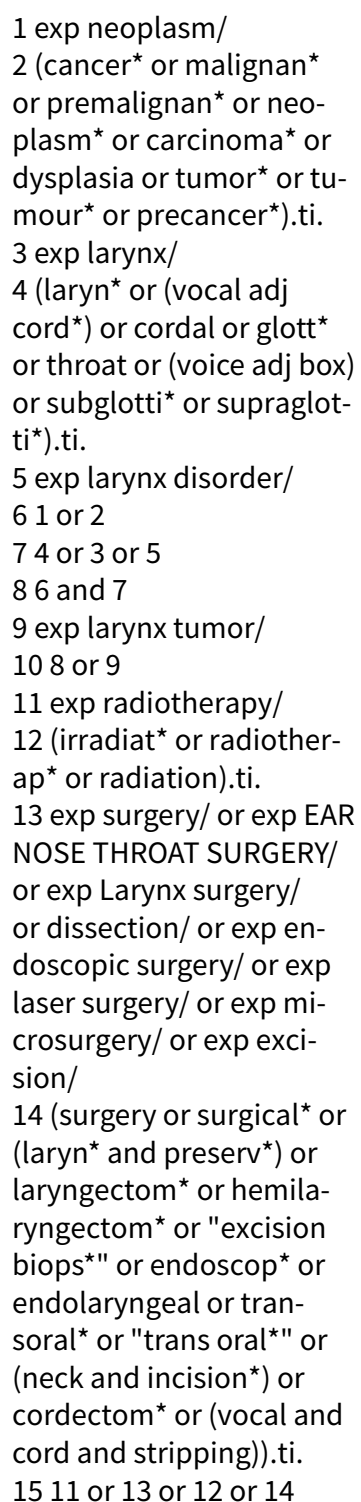 \\
\hline
\end{tabular}


$\# 1 \mathrm{TI}=\left(\right.$ cancer $^{\star}$ or malignan ${ }^{\star}$ or premalignan ${ }^{\star}$ or neoplasm ${ }^{\star}$ or carcinoma* or dysplasia or tumor ${ }^{\star}$ or tumour ${ }^{\star}$ or precancer $\left.{ }^{\star}\right)$

\#2 $\mathrm{Tl}=\left(\right.$ laryn $^{\star}$ or (vocal adj cord*) or cordal or glott* or throat or (voice adj box) or subglotti* or supraglotti*)

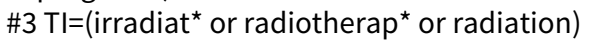
\#4 Tl=(surgery or surgical ${ }^{\star}$ or (laryn* and preserv $^{\star}$ ) or laryngectom ${ }^{\star}$ or hemilaryngectom ${ }^{\star}$ or "excision biops*" or endoscop* or endolaryngeal or transoral* or "trans oral ${ }^{\star}$ " or (neck and incision $^{\star}$ ) or cordectom* or (vocal and cord and stripping))

\#5 \#2 AND \#1

\#6 \#4 OR \#3

\#7 \#6 AND \#5
$\mathrm{S} 1$ (MH "Neoplasms+")

S2 TX cancer ${ }^{\star}$ or malignan* or premalignan* or neoplasm ${ }^{\star}$ or carcinoma* or dysplasia or tumor ${ }^{\star}$ or tumour ${ }^{\star}$ or precancer ${ }^{\star}$

\section{S3 S1 or S2}

S4 (MH "Larynx+")

S5 TI laryn* or vocal or glott* or throat or voice or subglotti* or supraglotti ${ }^{\star}$

$\mathrm{S} 6 \mathrm{~S} 4$ or S5

S7 S3 and S6

S8 (MH "Laryngeal Neoplasms")

S9 $\mathrm{S} 7$ or $\mathrm{S} 8$

S10 (MH "Radiotherapy+")

S11 TI irradiat* OR radiotherap* OR radiation

S12 (MH "Surgery, Operative")

S13 TI surgery OR surgical* OR (laryn* AND preserv $^{\star}$ ) OR laryngectom* OR hemilaryngectom * OR (excision AND biops ${ }^{\star}$ ) OR endoscop ${ }^{\star}$ OR endolaryngeal OR transoral ${ }^{\star}$ OR (trans AND oral*)OR (neck AND incision ${ }^{\star}$ ) OR cordectom* OR (vocal AND cord AND stripping)

$\mathrm{S} 14 \mathrm{~S} 10$ or $\mathrm{S} 11$ or $\mathrm{S} 12$ or $\mathrm{S} 13$

S15 S9 and S14 laryn $^{\star}$ AND cancer ${ }^{\star}$ OR laryn* AND carcinom* OR laryngec ${ }^{\star}$ OR glott* AND cancer ${ }^{\star}$ OR glott ${ }^{\star}$ AND carcinom* OR voice AND cancer $^{\star}$ OR voice AND carcinom ${ }^{\star}$ OR vocal AND cancer $^{\star}$ OR vocal AND carcinom*

\section{WHAT'S NEW}

\begin{tabular}{lll}
\hline Date & Event & Description \\
\hline 20 October 2014 & $\begin{array}{l}\text { New citation required but conclusions } \\
\text { have not changed }\end{array}$ & $\begin{array}{l}\text { We identified no new studies for inclusion in the review. One } \\
\text { study is ongoing (Saedi 2007). }\end{array}$ \\
& $\begin{array}{l}\text { There were no changes to the conclusions of the review. } \\
\text { We updated the study quality assessment method to the } \\
\text { Cochrane 'Risk of bias' tool. }\end{array}$ \\
& $\begin{array}{l}\text { We updated the 'Background', 'Discussion' and 'Implications for } \\
\text { practice and research' sections to reflect current clinical practice } \\
\text { and the decisions that patients and practitioners have to make in } \\
2014 .\end{array}$ \\
\hline 18 September 2014 & New search has been performed & New searches run. \\
\hline
\end{tabular}

\section{H ISTORY}

Protocol first published: Issue 2, 2000

Review first published: Issue 2, 2002 


\begin{tabular}{lll}
\hline Date & Event & Description \\
\hline 2 June 2010 & New search has been performed & $\begin{array}{l}\text { New searches run 1 October 2009. No new studies were included } \\
\text { in the review. We identified two further ongoing studies. }\end{array}$ \\
\hline 26 October 2008 & Amended & Converted to new review format. \\
\hline 22 August 2007 & New search has been performed & $\begin{array}{l}\text { New search carried out April 2007. No new studies found. The } \\
\text { authors are now aware of two ongoing studies which may be in- } \\
\text { cluded in future updates of this review. }\end{array}$ \\
\hline 25 August 2004 & New search has been performed & New searches November 2003. No new studies identified. \\
\hline
\end{tabular}

\section{CONTRIBUTIONS OF AUTHORS}

Janet Wilson (previous author), RW and KMacK were responsible for the conception of the review. PD and DA planned the first electronic search and screened the abstracts. PD, supported by Gemma Sandberg from the Cochrane ENT Group, planned the second electronic search and PD and KMacK screened the trials. The third and fourth electronic searches were conducted by Carolyn Doree from the Cochrane ENT group and PD assessed the abstracts. RW and KMacK assessed the trials. All authors discussed the review. PD extracted data. The first draft of the manuscript was completed by PD. All authors commented on the manuscript and agreed the final draft. PD updated the review. In 2014 an update was undertaken with searches performed by Gemma Sandberg and Samantha Faulkner. Laura Warner and Jessal Chudasama screened the results in conjunction with Paola Dey. Laura Warner, Paola Dey and Sean Loughran updated the text of the review. DA has retired.

\section{DECLARATIONS OF INTEREST}

KMacK and RW are members of the UK feasibility study comparing the effectiveness of radiotherapy and endoscopic excision (with or without laser) (EaStER). Laura Warner, Paola Dey, Sean Loughran, Jessal Chudasama and Charles Kelly do not have any known conflicts of interest,

\section{SOURCES OF SUPPORT}

\section{Internal sources}

- Freeman Hospital Trustees, Newcastle upon Tyne, UK.

\section{External sources}

- No sources of support supplied

\section{DIFFERENCES BETWEEN PROTOCOLANDREVIEW}

We updated the assessment of risk of bias in the included studies in 2014 to the Cochrane 'Risk of bias' method. We separated outcomes into 'primary' and 'secondary' and added information regarding potential future data synthesis.

\section{INDEX TERMS}

\section{Medical Subject Headings (MeSH)}

Carcinoma, Squamous Cell [mortality] [pathology] [ ${ }^{\star}$ radiotherapy] [ ${ }^{*}$ surgery]; Disease-Free Survival; Glottis [surgery]; Laryngeal Neoplasms [mortality] [pathology] [ ${ }^{\star}$ radiotherapy] [* surgery]; Laser Therapy; Randomized Controlled Trials as Topic

\section{MeSH check words}

Humans 